\title{
THE ROLE OF SOCIAL INSTITUTIONS IN THE ACTIVITY OF ENTREPRENEURS IN THE CONSTRUCTION SECTOR
}

\author{
Sergey Oparin, ${ }^{1}$ Nikolay Chepachenko, ${ }^{2}$ Marina Yudenko ${ }^{3}$
}

\begin{abstract}
This paper reports on a study of the methodological principles and roles of social institutions in controlling business activities. The level of their administrative interference in business activities is analyzed, particularly regarding administrative barriers restricting business in the construction sector. The study concludes that social institutions, on the one hand, reduce economic risks of entrepreneurship and encourage the fulfilling of formal norms. However, on the other hand, they perform a restrictive function, increasing entrepreneurs' transactional costs. The paper provides examples of informal norms that restrict entrepreneurial activity in the construction field, with a conclusion about non-systemic business support measures.
\end{abstract}

JEL Classification Numbers: M21, M48, B 52; DOI: http://dx.doi.org/10.12955/cbup.v5.948

UDC Classification: 338.246 .025 .2

Keywords: economic risk, entrepreneurship, social institutions, construction.

\section{Introduction}

The relevance of studying social institutions arises because of the significant risks associated with business activity in the construction sector. Social institutions are norms and rules that regulate and coordinate business activities, and reduce the risks of entrepreneurs. In principle, these business risks appear to be the bane of entrepreneurs in regards to their economic freedom. Such freedom coincides with that of others and thus, an entrepreneur's risk will increase as their market relationships develop. Therefore, the logical question is whether social institutions can influence the level of risk in business activity.

Presently, existing institutions fail to meet market conditions of Russia and hence, fall short of the expected growth in productivity for business entities. This prevails because of a construction sector that is characterized by a low index of entrepreneurial confidence, a significant number of unprofitable organizations, and serious indebtedness of entrepreneurs to the state and counteragents.

This article presents a review of the social institution based on the view that it represents formal norms or a set of norms that are stable in relation to the interests of economic entities. These norms coordinate, regulate, and restrict institutional relations between economic entities that carry out organizational, production, and exchange functions, as well as create conditions for effective business activity. The article does not examine the concept of a social institution as such, since this topic has no current cause for special discussion among scientists.

\section{Literature Review}

The analysis of the institutions, institutional structures, and their interaction with the state is covered in the works of Nobel laureates (North, 1997; Stigler, 1995; Hayek, 2006). Hayek (2006) provides elements of institutionalism that deserve mention. Hayek (2006) notes: "Legislation, the intentional creation of laws was fairly called the most important invention by its far-reaching consequences, and even more significant than fire and gunpowder" (p.91). The scientist divides the institutions into formal and informal ones, though, not as a clear definition. He writes about informal rules as follows:

People learned to observe the rules of conduct (and to seek their observance) long before these rules have been expressed in words" (p. 97).

Auzan and Nikishena (2013) emphasize that formal and informal institutions differ by way of coercion and enforcement. An informal institution is one where any individual who believes that

\footnotetext{
${ }^{1}$ Head of the Chair of Economics and management in the construction Petersburg State Transport University Emperor Alexander I, Saint-Petersburg, Russia, oparinsg@mail.ru

${ }^{2}$ Department of Economics and management in construction Petersburg State Transport University Emperor Alexander I, Saint-Petersburg, Russia,nvchepachenko@mail.ru

${ }^{3}$ Department of Economics and management in construction Petersburg State Transport University Emperor Alexander I, Saint-Petersburg, Russia, mnuspb@mail.ru
} 
the rule in question is to be carried out forces an individual to do so. Moreover, formal norms are specially developed rules of conduct that are codified in laws, decrees, and administrative documents.

Investigating the fundamental work of Knight (2003) within the concept of entrepreneurship, one should pause on an important aspect, i.e., the role of risk and uncertainty in entrepreneurship. From Knight's point of view, the existence of a unique future uncertainty may allow an entrepreneur to profit, despite the overall competition and long-term stability. Knight emphasizes the difference between the terms of 'risk' and 'uncertainty.' If uncertainty is countable, then such risks can be shifted to the shoulders of others through insurance. Such risks become a cost item that diminishes profits, but not their source.

Such Russian scientists as Polterovich (2012), Shastitko (2010), and many others, with interdisciplinary expertise suitable for examining the role of social institutions in the activities of entrepreneurs, should be noted here. Observation of their works provides the basis for the theory that the effectiveness of entrepreneurship within a country mainly depends on the institutional environment in which it is developed, i.e., the restrictive links and motivations of the institution. According to Shastitko (2010), a new institutional approach allows the existence of an entrepreneurial function, though not exclusively within existing rules, but rather in connection with potential changes. Hence, in explaining a change in rules that mediate the interaction between economic agents, the term of institutional entrepreneurship is used.

In the framework of the research, it was considered important to extend the notion of 'entrepreneurship' and to consider it not in the usual, but in a generalized sense. Entrepreneurship in the generalized sense reflects the totality of economic, social, organizational, and institutional relations associated with the entrepreneurial business organization, producing goods (works and services) and obtaining the desired results in the form of profit. Such understanding makes it necessary to account the social component in entrepreneurial activity, i.e., the external environment in the form of social institutions. This then reduces the risk and uncertainty of business and creates conditions for achieving the goals of entrepreneurs in productivity growth and economic efficiency.

\section{Duality of the Social Institution's Impact on Entrepreneurship}

The final result of the activity of social institutions can be deemed as the creation of a clear status-role structure based on the norms and rules, socially approved by the majority of participants of this social process. However, it should not be considered that state regulatory and coordinate norms fully facilitate the life of an entrepreneur and exclude possible risks in economic activities. These norms also perform a restrictive function. For example, since 2016, quarterly reports to the Pension Fund of Russia have been replaced by monthly ones, causing the staff to learn new forms of reporting. Changes also relate to statistical reporting, as there are more than 300 federal statistical forms. These serve to collect information about the finances, number, and salary of employees, the commissioning of buildings and structures in the construction sector.

Due to the existence of informal norms, the results of implementing formal norms can be different. For example, where the majority of entrepreneurs denounce tax evaders, then with the same force of compulsion to pay, the percentage of tax defaulters will be lower than in a society where tax evasion is considered an imitation. Formation of a taxation institution is designed to reduce the transactional costs by its implementation. Such costs are associated with completing a tax return, queueing for its submission, visiting tax authorities, and the transparency of the rules. In Russia, a tax report with attachments includes about 100 pages of text and calculations, and a declaration for each tax has a volume of up to 20 sheets. Designers constantly change the tax declaration forms, because, in their opinion, all provisions of the Tax Code and all new documents regulating the payment of taxes should be taken into account in the form. Such an approach may not be the most justified. An example of transactional costs is evident where the position of taxpayers has been significantly complicated by the introduction of the twenty-figure budget classification codes. Each tax penalty or fine is assigned with a code that is constantly changed. Recording a wrong code when signing out a payment order or processing information in a tax inspection, results in the payment being categorized as 'unclear.' In this case, penalties are charged for each day a payment is allegedly delayed. To clarify the situation, a taxy payer needs to reconcile their data with that of the tax inspectors, but due to work overload of 
inspectors, it is almost impossible to carry out such reconciliation in time. Nevertheless, changes in the legislation will create an incentive to implement formal norms. The penalty for not providing or improperly presenting statistical data has increased tenfold. Previously, it was between 3000 and 5000 RUB. Now, legal entities have to pay between 20000 and 70000 RUB. For a repeated violation, this payment is between 100000 and 150000 RUB.

However, the current Russian legislation also provides such formal norms that exclude risks associated with the emergence of both transformational and transactional costs. For example, new rules governing entrepreneurial activity in 2016 will help business entities obtain additional profits and reduce the risks of bankruptcy and non-payment. Based on the simplified taxation system, such norms include the following:

- Local authorities can reduce the tax rate for entrepreneurs from $6 \%$ to $1 \%$;

- Organizations and individual entrepreneurs may not include vat in their income.

\section{Methodological Rules Determining the Activity of Entrepreneurs}

Any business activity directly depends on the methodological rules that determine it. These may include inadequate and changeable information, unfinished contracts, and the incomplete specification of property rights.

Inadequate Information

The market is far from flawless; transactions of entrepreneurs are worth certain costs, which are connected with the acquisition of information. Many economists believe that limited and useful information for economic entities gives grounds to classify it as a factor of production, along with land, capital, and labor. Scientists believe there are two principal reasons for inadequate information from an economic viewpoint. First, the selection of comprehensive information is possible, but not profitable. Second, the full information is impossible to obtain. Thus, the lack of profound information makes the activity of entrepreneurs risky and opportunistic.

The base of opportunistic behavior consists of information asymmetry and uncertainty. A business partner cannot know all the circumstances and intentions of another partner on the eve of the contract conclusion and, moreover, cannot know all the details of the partner's behavior after the contract has been concluded. Therefore, opportunism is always based on the inadequate or distorted information that the subject of opportunistic behavior provides to a business partner before or after the start of the contract. The initial principle of the institutional theory is to pay for information. If all business entities had unrestricted access to information, then they would have full knowledge of their partners' behavior and would be able to prevent any breach by partners, as well as avoid the risks of failure to comply with the entrepreneurial agreement. Then, the problem of opportunism would not be considered. However, due to the changeability and inadequate availability of information, monitoring compliance with the contract is difficult, and the parties attempt to obtain guarantees that are prescribed in the contract.

Stigler (1995) in Economic Theory of Information notes that:

It is hardly necessary to remind scientists that information is a valuable resource: knowledge is power. However, in the city, which is an economic theory, information huddles in the slums. For the most part, it is ignored: the best technology is already known; the ratio between the goods and the preferences of the buyers is considered to be settled (p. 507).

\section{Incomplete Specification of Property Rights}

Specification of property rights assumes a legal authority's security for each defined owner, rather than the single and absolute owner of the resource. The ownership right is fully specified when each authority has its exclusive owner, and access to it by other entities is limited. In Russia, $88.6 \%$ of the enterprises is private ownership, while $6.6 \%$ is state and municipality owned. The problem of property rights specification is regarded as a priority, and its relevance increases each year. The number of claims to the arbitration court about the right of ownership is steadily growing, as well as the number of applications for recognizing the right of ownership and reclaiming property from another. The dynamics of indicators confirm the conclusion that there is insufficient institutional security for the protection of property rights of entrepreneurs. 


\section{Unfinished Contracts}

All business activities of an entrepreneur consist of transactions, the basis of which is an exchange, in which goods (works, or services) are transferred from one entrepreneur to another, subject to a counter flow of money (benefits) or a commitment to transfer in the future. Where the conditions of such exchange are known in advance, then the exchange becomes a contract. A contract assumes existing mutual expectations. However, in practice, implementing contracts has high risk and uncertainty that leads to the incompleteness of contracts or their non-fulfillment. In practice, economic entities operate in a highly competitive environment, and benefits from contracts are low. Moreover, in this case, a contract cannot be self-sustaining, and its execution creates huge risks. It is clear that incompleteness of contracts leads to a risk of invalidity of the contracts.

\section{Administrative Barriers to the Activity of Entrepreneurs}

One current problem of the Russian economy is a high level of administrative barriers affecting the business activities of entrepreneurs. These administrative barriers are the rules about conducting certain activities in the market that have been established by decisions of state bodies for compliance, which is an indispensable condition for conducting such. At the same time, it provides payments to fund bureaucratic procedures that are not always identified in the budget. Yudenko and Leontiev (2017) note that the system of administrative and legal regulation in construction remains unfriendly to small- and medium-sized enterprises and does not take into account the specifics of doing business in small forms of management. Business costs associated with the need to meet regulatory requirements are constantly growing.

The construction faces several institutional norms that limit the construction of residential and commercial real estate. Access to land for building, and obtaining approvals and permits for connecting infrastructure, distort the conditions of competition and affect the construction period of a facility. Land plots are often provided with no engineering infrastructure, and the technical conditions are unaffordable for investors. The absence of master plans does not allow a municipal formation to systematically determine how it will develop the territory where construction is to be carried out. This influences the number of orders for construction and repair works that are performed by small businesses.

According to Oparin, Chepachenko, and Yudenko (2016), the problems of estimating costs in construction of buildings and other structures are also an administrative barrier that does not allow economic entities to increase productivity and efficiency in general.

The Russian small and medium business forum was held in Russia in 2015. The forum (Panel discussion of the forum "Reducing administrative barriers for doing business," 2015, June) identified two main reasons limiting the development of small- and medium-sized businesses: 1) administrative barriers that ensure legalization of corruption flows; and 2) monopolization of markets through administrative resources. The costs for small business owners regarding the problems mentioned above are transactional. It was announced at the forum that the cost of administrative barriers was 7\% of gross domestic product per year (i.e., 5628 billion RUB or 125 billion USD).

In regards to the problems, in particular, administrative barriers that ensure the legalization of corruption flows, there are several issues. Payments, due to the existence of such barriers, are not directly related to taxes but remain legal payments for various certificates or documents confirming unnecessary compliance, i.e., legal business and technology for issuing certificates and confirmations. On this issue, there is some opposition between supporters of the introduction of new regulatory measures and those who, on the contrary, favor the weakening of state regulation of small businesses. In difficult economic times, the popularity of both parties and their solutions are growing. Business representatives complain about the lack of funds for obtaining various approvals and permits. The crisis pushes the business into obscurity, while the sector authorities believe that it is possible to resist this process due to certain new permitting procedures. It is clear that the new procedures, as a rule, only increase the administrative burden on businesses and may indirectly send them into obscurity.

The second factor limiting the activity of economic entities is the monopolization of markets through administrative resources. Administrative monopoly arises from actions of state bodies. On the one hand, it grants individual enterprises the exclusive right to perform certain types of activities. Competition, in this case, is absent. On the other hand, the remaining enterprises in the market receive 
a high profit in favor of affiliated persons. Signs of monopolies or oligopolies in the housing construction market can be found in all major regions of the country where huge budget money is involved in construction in Moscow, the Moscow region, Saint Petersburg, the Leningrad region, and other regions. According to Kaplan (2016), the director of the Union of Construction Companies 'Soyuzpetrostroy', at present, the Northern Capital rates 29th (one of the last) as likely to enter the market of construction services.

\section{Conclusion}

In conclusion, costs of entrepreneurs usually have economic as well as ethical and political bases. Irrespective of the official goals of state and municipal bodies in relation to business, their daily activities are determined by decisions accepted by ordinary people through certain incentives, interests, and tasks. Likewise, one should be cautious about statements from entrepreneurs who attempt to convince society of their adherence to public interests, stating that their main criterion when formulating an enterprise policy is not the maximization of profits but the fulfillment of obligations to society. In addition to the above sources that determine costs of entrepreneurs, there is also the institutional dimension of business. Rationally created formal institutions should consider the 'human nature' of entrepreneurs and remain open to the growth of informal processes and mechanisms of insurance as entrepreneurs do not have effective mechanisms of insurance against formal norms of certain institutions (e.g., taxation, bankruptcy, and norms governing the process of obtaining a building permit). Gaps in the institutional space can lead to a situation of an official deciding upon the solution. Moreover, this choice may not be in favor of the entrepreneur and could be influenced by the relationship between the entrepreneur and the authorities. Such a situation is common in today's society, opens the field to corruption, and increases uncertainty of the economic environment. Furthermore, in the absence of sufficient funds in the budget, possibly only the confidence of entrepreneurs and a favorable investment climate will attract private capital for small businesses in the economy. For promoting small business development, it is recommended that the state apply several basic institutional rules. First, the state could disallow property access rights to those who do not own the property by law. This rule would avoid entrepreneurs bearing the high cost of insuring against third parties access to their properties. Such costs can exceed the potential incomes of the economic entity. Second, where entrepreneurs do not accept official institutions, they could be guided by informal norms, depending on the state of the economic environment. Where the market economy is characterized by a predominance of personified norms, spontaneously formed institutions in the field of pricing, investment, construction, and exchange arise followed by institutional contradictions and confines. In this case, when the behavior of entrepreneurs is regulated by a volitional establishment of general norm, and not by a separate agreement of parties, entrepreneurs face a regulatory act or law. Therefore, a mechanism of norms for compliance is necessary, the action of which should not limit an entrepreneur's profit and would be aimed at increasing efficiency. Third, abolishing unnecessary restrictions and permits, i.e., removing administrative barriers, would be an easy way to increase the value of an entrepreneur's property (land, fixed assets, real estate, and objects of intellectual value) and allow the opportunity for his or her effective action. Currently, most of the adopted laws and regulations are beneficial only to one party, the legislator, and those supporting it. Finally, forming a single, complete mechanism for administering tax, customs, and other fiscal payments could eliminate inefficient controls. State bodies should consider counting the costs of entrepreneurs. Today, every 1 RUB of the legal wage of an employee incurs up to $0.55-0.60$ RUB in taxes.

\section{References}

Auzan, A. A., \& Nikishena, E. N. (2013). Long-term economic dynamics: the role of informal institutions. Economic theory, 2013, 48-57.

Hayek, F. (2006). Law, Legislation and Liberty: A New Statement of the Liberal Principles of Justice and Political Economy. Moscow: IRISEN.

Kaplan, L. Competition in construction is not developed: the market of St. Petersburg is monopolized. [Web blog post]. Retrieved March 25, 2016, from: http://razned.ru/urban-property/article/competition-in-construction-is-not-developed-the-stpetersburg-market-is-monopolized/.

Knight, F.H. (2003). Risk, uncertainty and profit. Moscow: Business.

North, Douglass (1997). Institutions, institutional change and economic performance. Moscow: Fund of the economic book Elements. 
Oparin, Sergey, Chepachenko, Nikolay \& Yudenko, Marina (2016). Problems in forming cost estimates for construction industry. International Conference Proceedings 2016 - Innovation in science and education. Central Bohemia University. 179-186.

Polterovich V.M. (2012). Designing Reforms: How to Look for Intermediate Institutions. Montenegrin Journal of Economics, 8, 2, 25-44.

Russian Forum of small and medium business. Panel session "Reduction of administrative barriers for doing business". Retrieved June 15, 2015, from: https://www.youtube.com/watch?v=bCtAvQWDxv0.

Shastitko, A.E. (2010). New institutional economic theory. Moscow: TEIS.

Stigler, J. (1995). Economic theory of information. The theory of the firm. Saint Petersburg: Economic school.

Yudenko, M.N., Leontiev, A.A. (2017). Institutional problems of small business in construction. Economics of construction. $1,15-22$. 